Check for updates

Cite this: RSC Adv., 2019, 9, 7057

Received 6th December 2018 Accepted 23rd February 2019

DOI: $10.1039 / c 8 r a 10037 c$

rsc.li/rsc-advances

\section{Non-isothermal crystallization, yellowing resistance and mechanical properties of heat- resistant nylon 10T/66/titania dioxide/glass fibre composites}

\begin{abstract}
Bingxiao Liu, ${ }^{a}$ Guosheng Hu, (D) *a Jingting Zhang ${ }^{a}$ and Wen Yan ${ }^{b}$
Herein, we report novel heat-resistant nylon 10T/66/titania dioxide/glass fibre (nylon 10T/66/TiO $2 / G F$ ) composites based on as-synthesised nylon 10T/66, which is a copolymer of poly(decamethylene terephthalamide) (nylon 10T). The non-isothermal crystallization behaviors of nylon 10T/66 and nylon $10 \mathrm{~T} / 66 / \mathrm{TiO}_{2} / \mathrm{GF}$ composites were investigated by differential scanning calorimetry (DSC). Jeziorny and Mo equations were used to analyse the crystallization kinetics, whereas the Kissinger method was applied to calculate the activation energy. It turned out that the introduction of $\mathrm{TiO}_{2}$ and GF could accelerate the crystallization of nylon 10T/66 and exhibited an effective heterogeneous nucleation effect. In addition, we conducted yellowing resistance and mechanical property analysis of the nylon $10 \mathrm{~T} / 66 / \mathrm{TiO}_{2} / \mathrm{GF}$ composites. The above results successfully demonstrated that the heat-resistant nylon $10 \mathrm{~T} / 66 / \mathrm{TiO}_{2} / \mathrm{GF}$ composites possess higher crystallization temperature and crystallization rate, whiter color, and better yellowing resistance and mechanical properties than previously as-synthesised nylon 10T/66. Consequently, nylon $10 \mathrm{~T} / 66 / \mathrm{TiO}_{2} / \mathrm{GF}$ composites have great potential to be used as a heatresistant engineering plastic.
\end{abstract}

\section{Introduction}

Semi-aromatic nylon, combining the superior thermal stability of aromatic nylon and the excellent melt processability of aliphatic nylon, has been widely applied in the field of electronics (e.g., connectors, surface mount devices and reflectors) and automobile parts (e.g., powertrain components). ${ }^{1,2}$ Typical commercial semi-aromatic nylon includes poly(hexamethylene terephthalamide) (nylon 6T) copolymers (Dupont, Solvary et al.), poly(nonamethylene terephthalamide) (nylon 9T) (Kuraray) and nylon 10T (Kingfa and Zenong). Among them, nylon 10T is the only bio-based semi-aromatic heat-resistant nylon. ${ }^{3}$ However, the melting point of nylon $10 \mathrm{~T}\left(316^{\circ} \mathrm{C}\right)$ is relatively close to its initial decomposition temperature $\left(350{ }^{\circ} \mathrm{C}\right)$ which makes conventional melt processing impractical. ${ }^{4}$ Consequently, we introduced the aliphatic nylon 66 chains into the backbones of nylon 10T, and obtained nylon 10T/66 copolymer, ${ }^{5,6}$ which possesses better melt processability.

However, the yellower color, poor yellowing resistance and mechanical properties limit the application of the neat nylon

${ }^{a}$ Institute of Macromolecules and Bioengineering, School of Materials Science and Engineering, North University of China, Taiyuan 030051, China

${ }^{b}$ Public Service Platform for Science and Technology, Shenzhen Institutes of Advanced Technology, Chinese Academy of Sciences, Shenzhen University Town, 1068 Xueyuan Avenue, Shenzhen 518055, PR China
10T/66. As we all know, blending is the most common and effective way to improve polymer performance. ${ }^{7}$

Glass fiber (GF), due to its high strength and low price, has become one of the most extensive reinforcement materials. ${ }^{8,9} \mathrm{Li}$ et al. investigated the effect of GF addition on mechanical properties of poly(arylene ether nitriles), and found the tensile strength, flexural strength and izod impact strength of poly(arylene ether nitriles) were sharply increased in the presence of GF. ${ }^{10}$ Titania dioxide $\left(\mathrm{TiO}_{2}\right)$ is applied as whiteners in a variety of polymeric composiions. ${ }^{11}$ Wang et al. added $\mathrm{TiO}_{2}$ into knitted fabric, which successfully improved its color and yellowing resistance. ${ }^{12}$

At present, many papers have studied the mechanical properties of GF reinforced nylon, and lots of researches have reported the improvement of the yellowing resistance of $\mathrm{TiO}_{2}$ to nylon, however, to the best of our knowledge, there has been no report that $\mathrm{GF}, \mathrm{TiO}_{2}$ and nylon resin are ternary blended to simultaneously improve their mechanical properties and yellowing resistance properties. In this paper, we prepared nylon $10 \mathrm{~T} / 66 / \mathrm{TiO}_{2} / \mathrm{GF}$ by blending as-synthesised nylon $10 \mathrm{~T} / 66$ with $\mathrm{GF}$ and $\mathrm{TiO}_{2}$. The morphological structures of nylon 10T/66/ $\mathrm{TiO}_{2} / \mathrm{GF}$ were observed by scanning electron microscopy (SEM). In order to investigate the effect of $\mathrm{GF}$ and $\mathrm{TiO}_{2}$ on the crystallization of polymers and better understand the relationship between the structure and properties of materials, it is essential to study the crystallization kinetics, especially the non- 
isothermal crystallization kinetics, which is closer to the actual processing condition. ${ }^{\mathbf{1 3}, \mathbf{1 4}}$ The non-isothermal kinetics parameters of nylon $10 \mathrm{~T} / 66 / \mathrm{TiO}_{2} / \mathrm{GF}$ were carried out using the Jeziorny $^{15}$ and the Mo equations. ${ }^{16}$ The non-isothermal crystallization activation energy was calculated by Kissinger method. ${ }^{17}$ In addition, the yellowing resistance and the mechanical properties of nylon $10 \mathrm{~T} / 66 / \mathrm{TiO}_{2} / \mathrm{GF}$ composites were also assessed and reported here.

\section{Experimental}

\subsection{Materials}

Decamethylenediamine (DA10), hexamethylene diamine (HMD) and adipic acid were supplied by Wuxi Yinda Nylons Co. Ltd. (Wuxi, China). The terephthalic acid (PTA) was purchased from Beijing Yanshan Lithification Chemical Co. Ltd. (Beijing, China). The benzoic acid (BA) was bought from Tianjin Kai Tong Chemical Reagent Co., Ltd (Tianjin, China). Taishan Fiberglass Inc. and DuPont provided the GF and $\mathrm{TiO}_{2}$ (Ti-pure $\mathrm{R}-103$, rutile), respectively.

\subsection{Synthesis of nylon 10T/66}

DA10 (172.3 g, $1 \mathrm{~mol})$, PTA (166.1 g, $1 \mathrm{~mol})$, BA ( $4.6 \mathrm{~g}, 0.038 \mathrm{~mol})$ and nylon 66 salt $(13.1 \mathrm{~g}, 0.05 \mathrm{~mol})$ were added into an autoclave. To reduce volatilization of diamine during polymerization, boiled distilled water $(100 \mathrm{~mL})$ was added. BA is used to control the molecular weight of copolymers. Then, the autoclave was purged with $\mathrm{N}_{2}$ for $5 \mathrm{~min}$. At a pressure of about $0.4 \mathrm{MPa}$ pressure and a $300{ }^{\circ} \mathrm{C}$ set point, the mixture temperature remained at $125{ }^{\circ} \mathrm{C}$ until all water evaporated. This stage promotes the homogenization of the reaction mixture, with almost no polymerization. When the reaction temperature reached $273{ }^{\circ} \mathrm{C}$, meanwhile the pressure was up to $2.0 \mathrm{MPa}$, the heater set point was changed to $330^{\circ} \mathrm{C}$ and the temperature was allowed to rise and hold at $280^{\circ} \mathrm{C}$. After allowing to react for $2 \mathrm{~h}$, the pressure of the autoclave was gradually released to atmospheric pressure in $1 \mathrm{~h}$ and the reaction temperature of the sample was increased to $320{ }^{\circ} \mathrm{C}$. Then the pressure of the autoclave was evacuated to $-0.09 \mathrm{MPa}$. The reaction was continued for another $0.6 \mathrm{~h}$ and the copolymers were obtained.

\subsection{Preparation of nylon $10 \mathrm{~T} / 66 / \mathrm{TiO}_{2}$, nylon $10 \mathrm{~T} / 66 / \mathrm{GF}$ and nylon $10 \mathrm{~T} / 66 / \mathrm{TiO}_{2} / \mathrm{GF}$}

Nylon 10T/66, $\mathrm{TiO}_{2}$ and GF were extruded from twin-screw extruder. Each region temperature was 300, 305, 305, and $295{ }^{\circ} \mathrm{C}$, respectively. The screw speed was $40 \mathrm{rpm}$. The detailed dosages are presented in Table 1.

Table 1 Composition of nylon 10T/66/ $\mathrm{TiO}_{2}$, nylon 10T/66/GF and nylon $10 \mathrm{~T} / 66 / \mathrm{TiO}_{2} / \mathrm{GF}$

\begin{tabular}{lllr}
\hline Samples & Nylon10T/66/g & $\mathrm{TiO}_{2} / \mathrm{g}$ & $\mathrm{GF} / \mathrm{g}$ \\
\hline Nylon $10 \mathrm{~T} / 66 / \mathrm{TiO}_{2}$ & 700 & 200 & 0 \\
Nylon $10 \mathrm{~T} / 66 / \mathrm{GF}$ & 700 & 200 & 0 \\
Nylon $10 \mathrm{~T} / 66 / \mathrm{TiO}_{2} / \mathrm{GF}$ & 700 & 200 & 200
\end{tabular}

\subsection{Characterization of nylon $10 \mathrm{~T} / 66 / \mathrm{TiO}_{2} / \mathrm{GF}$ composites}

${ }^{1} \mathrm{H}$ NMR, Bruker DPX-400 at $400 \mathrm{MHz}$, was applied to identify the chemical structure of nylon $10 \mathrm{~T} / 66$, using deuterated trifluoroacetic acid as solvents.

In order to improve conductivity, all samples were coated with gold before testing. The surface morphology was performed by cross-section scanning electron microscopy (SEM, MIRA3 FE-SEM, Czech) with an Oxford energy dispersive spectrometer (EDS).

DSC measurements were carried out on a Mettler $822 \mathrm{e}$ equipped with a STAR system, and calibrated with an indium standard. All measurements were under a nitrogen atmosphere $\left(50 \mathrm{~mL} \mathrm{~min}{ }^{-1}\right)$. Sample with mass of $3 \mathrm{mg}$ was heated from $25{ }^{\circ} \mathrm{C}$ to $320{ }^{\circ} \mathrm{C}$ at a rate of $50{ }^{\circ} \mathrm{C} \min ^{-1}$ and held this temperature for $5 \mathrm{~min}$ in order to eliminate the thermal history. After that, the sample was cooled to $30{ }^{\circ} \mathrm{C}$ at different cooling rates of $5,10,20$ and $30{ }^{\circ} \mathrm{C} \min ^{-1}$, respectively. Record the nonisothermal crystallization curves as a function of time.

We injected the standard color plates using the injection moulding machine (HF-036). Then plates were put into the blast oven at the set temperature of $180{ }^{\circ} \mathrm{C}$ for 0 and 2 hours respectively. The CIELAB color parameters were performed under the Color i5 spectrophotometer. In the CIELAB system, the $L, b$ denote the white-black value and yellow-blue of the materials, respectively.

The standard mechanical test samples of nylon $10 \mathrm{~T} / 66 / \mathrm{TiO}_{2}$, nylon $10 \mathrm{~T} / 66 / \mathrm{GF}$ and nylon $10 \mathrm{~T} / 66 / \mathrm{TiO}_{2} / \mathrm{GF}$ were prepared by an injection molding machine (HF-036). The tensile and bending properties were measured by Universal Testing Machine CMT6104 according to the ISO527 and ISO178. The impact property was tested on the basis of ISO179 by an impact testing machine XJU-22.

\section{Results and discussion}

\subsection{Synthesis of nylon 10T/66}

The chemical structure of nylon $10 \mathrm{~T} / 66$ is determined by ${ }^{1} \mathrm{H}$ NMR spectra (Fig. 1). The chemical shifts, in the range of 3.71$3.62 \mathrm{ppm}$, originate from the protons of methylene adjacent to

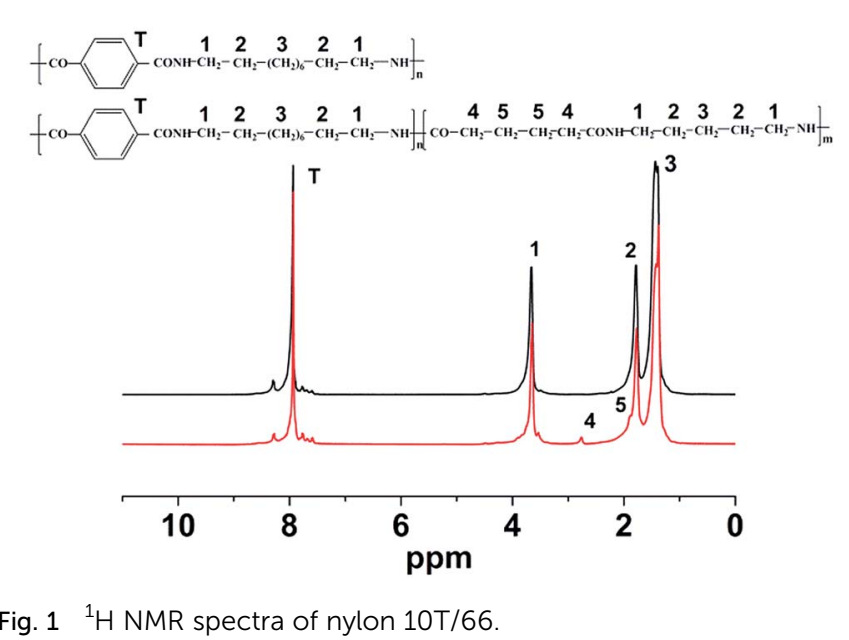


the $\mathrm{NH}$ group (position 1). The peaks at 1.82-1.75 ppm and 1.48-1.34 can be attributed to the position 2 and 3, respectively. The chemical shifts at 7.96-7.93 ppm correspond to the aromatic protons (position $\mathrm{T}$ ). It is worth noting that the chemical shifts of nylon 10T/66 at $2.76 \mathrm{ppm}$ and $1.89 \mathrm{ppm}$ correspond to the positions 4 and 5, respectively, which indicates the formation of nylon 10T/66. After testing, the melting point of nylon $10 \mathrm{~T} / 66\left(305^{\circ} \mathrm{C}\right)$ is lower than that of neat nylon $10 \mathrm{~T}\left(316^{\circ} \mathrm{C}\right)$, suggesting that nylon $10 \mathrm{~T} / 66$ possesses better processability.

\subsection{SEM and EDS analysis of nylon $10 \mathrm{~T} / 66 / \mathrm{TiO}_{2} / \mathrm{GF}$}

SEM and EDS images shown in Fig. 2 are applied to evaluate the dispersion of the $\mathrm{GF}$ and $\mathrm{TiO}_{2}$ in the nylon 10T/66 matrix. In Fig. 2A, the GF phases, which are cylindrical, are well wrapped by the nylon matrix. The white substances in Fig. $2 \mathrm{~B}$ are $\mathrm{TiO}_{2}$, and it can be clearly seen that $\mathrm{TiO}_{2}$ is well dispersed in the matrix. SEM results indicated the excellent compatibility between the $\mathrm{TiO}_{2}$, GF and matrix resin in nylon $10 \mathrm{~T} / 66 / \mathrm{TiO}_{2} / \mathrm{GF}$.

Fig. $2 \mathrm{C}$ and $\mathrm{D}$ represent the EDS dot map distribution images of the titanium and silicon in nylon $10 \mathrm{~T} / 66 / \mathrm{TiO}_{2} / \mathrm{GF}$, respectively. As shown in these two figures, both titanium and silicon elements were uniformly distributed in the nylon matrix (silicon element is derived from GF), suggesting that the outstanding dispersion of the $\mathrm{TiO}_{2}$ and GF in nylon matrix resin, which is similar to the SEM results.

\subsection{FT-IR analysis}

The FT-IR spectrums of different samples are presented in Fig. 3. The absorbance peaks appeared at $3297 \mathrm{~cm}^{-1}$ are compounding to stretching vibration of $\mathrm{N}-\mathrm{H}$, and the peaks at $2926 \mathrm{~cm}^{-1}$ and $2857 \mathrm{~cm}^{-1}$ represent asymmetric and symmetrical stretching vibration of $-\mathrm{CH}_{2}$ respectively. Moreover, the absorption bands of amide can be reflected in these spectrums. In detail, the stretching vibration of $\mathrm{C}=\mathrm{O}, \mathrm{C}-\mathrm{N}$ and $\mathrm{C}-\mathrm{CO}$ are observed at 1626, 1380 and $1018 \mathrm{~cm}^{-1}$ respectively, and the in-
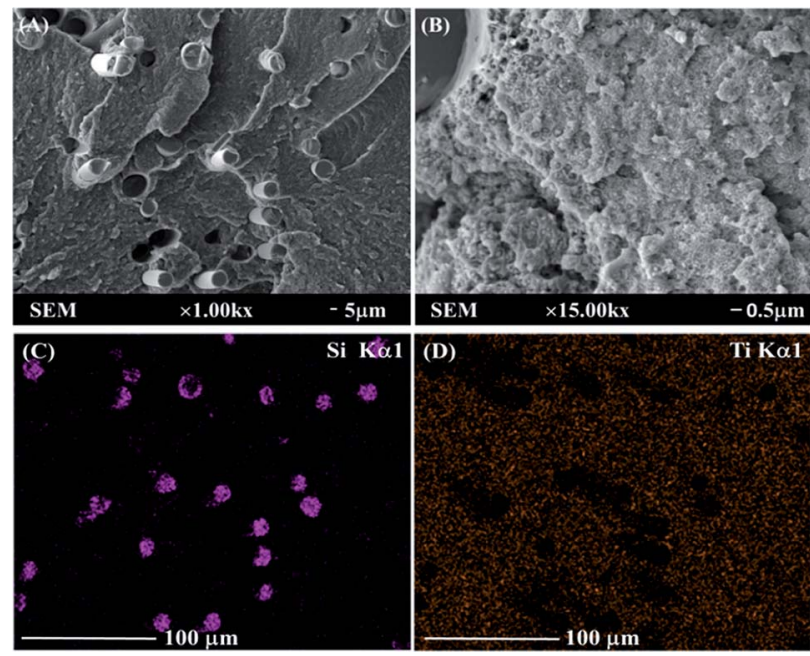

Fig. 2 SEM and EDS photos of nylon $10 \mathrm{~T} / 66 / \mathrm{TiO}_{2} / \mathrm{GF}$.

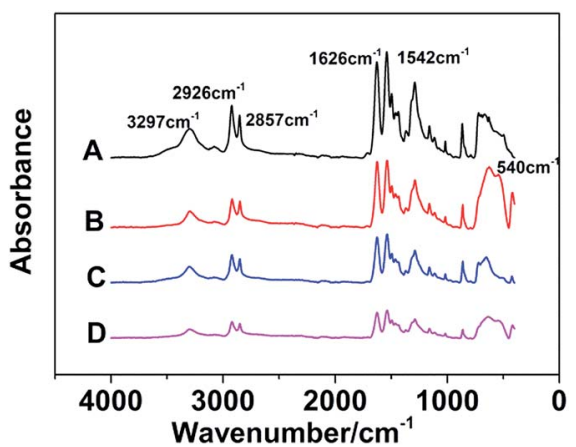

Fig. 3 The FT-IR spectrums of nylon 10T/66 (A), nylon 10T/66/TiO 2 (B), nylon 10T/66/GF (C) and nylon 10T/66/TiO $/ 2 / G F(D)$.

plane flexural vibration of $\mathrm{N}-\mathrm{H}$ is revealed at $1542 \mathrm{~cm}^{-1}$. The absorbance peaks appeared at $864 \mathrm{~cm}^{-1}$ and $624 \mathrm{~cm}^{-1}$ are compounding to out-of-plane flexural vibration of $\mathrm{C}-\mathrm{H}$. In addition, the absorbance peak at $540 \mathrm{~cm}^{-1}$ is caused by $\mathrm{TiO}_{2}$. These results of absorbance peaks prove that both $\mathrm{TiO}_{2}$ and GF are without influence upon the chemical bonding structure of nylon $10 \mathrm{~T} / 66$.

\subsection{Non-isothermal crystallization analysis}

3.4.1 Non-isothermal crystallization behaviors of samples. The non-isothermal crystallization curves of nylon 10T/66, nylon $10 \mathrm{~T} / 66 / \mathrm{TiO}_{2}$, nylon $10 \mathrm{~T} / 66 / \mathrm{GF}$ and nylon $10 \mathrm{~T} / 66 / \mathrm{TiO}_{2} /$ GF at various cooling rate are shown in Fig. 4, and the crystallization peak temperatures $\left(T_{\mathrm{p}}\right)$ are summarized in Table 2 . It could be clearly found from Fig. 4 that for all samples, the crystallization temperature decreases significantly and the temperature range becomes wider with increasing cooling rate, which is a common phenomenon of semi-crystalline polymers. ${ }^{7,18}$ This suggests that the molecular chain does not
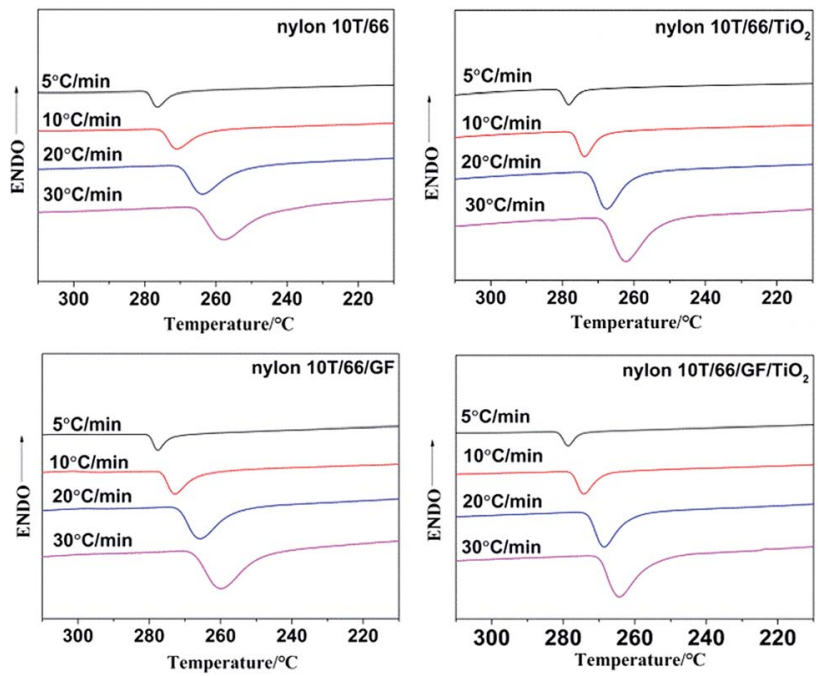

Fig. 4 Non-isothermal crystallization plots of nylon 10T/66, nylon 10T/66/ $\mathrm{TiO}_{2}$, nylon 10T/66/GF and nylon 10T/66/TiO $2 / \mathrm{GF}$. 
Table 2 Thermodynamic parameters of non-isothermal crystallization

\begin{tabular}{lllll}
\hline Sample & $\Phi /{ }^{\circ} \mathrm{C} \mathrm{min}^{-1}$ & $T_{\mathrm{p}} /{ }^{\circ} \mathrm{C}$ & $T_{1 / 2} / \mathrm{min}$ & $G$ \\
\hline Nylon 10T/66 & 5 & 276.39 & 0.71 & 1.41 \\
& 10 & 270.94 & 0.51 & 1.96 \\
& 20 & 263.71 & 0.38 & 2.63 \\
Nylon 10T/ $\mathrm{TiO}_{2}$ & 30 & 257.67 & 0.28 & 3.57 \\
& 5 & 278.23 & 0.49 & 2.04 \\
& 10 & 273.73 & 0.34 & 2.94 \\
Nylon 10T/66/GF & 20 & 267.62 & 0.25 & 4.00 \\
& 30 & 262.05 & 0.2 & 5.00 \\
& 5 & 277.68 & 0.58 & 1.72 \\
& 10 & 272.72 & 0.41 & 2.44 \\
Nylon 10T/66/TiO $/ \mathrm{GF}$ & 20 & 265.63 & 0.30 & 3.33 \\
& 30 & 260.05 & 0.25 & 4.00 \\
& 5 & 278.61 & 0.48 & 2.08 \\
& 10 & 274.37 & 0.33 & 3.03 \\
& 20 & 268.58 & 0.23 & 4.35 \\
& 30 & 264.50 & 0.19 & 5.26 \\
& & & &
\end{tabular}

have enough time to overcome the barrier to form crystal nuclei and perfect crystals at higher cooling rate. ${ }^{19,20}$ According to the Table 2, for a fixed cooling rate, the crystallization temperature of neat nylon $10 \mathrm{~T} / 66$ increases with the addition of $\mathrm{TiO}_{2}$ and GF, which indicates that $\mathrm{TiO}_{2}$ and GF play nucleating agent roles in accelerating the crystallization process of neat nylon $10 \mathrm{~T} / 66 .{ }^{13}$ Moreover, nylon $10 \mathrm{~T} / 66 / \mathrm{TiO}_{2} / \mathrm{GF}$ has the highest crystallization temperature, since $\mathrm{TiO}_{2}$ and GF have a synergistic.

3.4.2 Non-isothermal crystallization kinetics. Considering the effect of $\mathrm{TiO}_{2}$ and GF on the crystallization behavior of nylon $10 \mathrm{~T} / 66$, it is necessary to study the non-isothermal crystallization kinetics of nylon $10 \mathrm{~T} / 66 / \mathrm{TiO}_{2} / \mathrm{GF}{ }^{14}$ The relative crystallinity of nylon $10 \mathrm{~T} / 66 / \mathrm{TiO}_{2} / \mathrm{GF}$ at a certain temperature can be calculated by the ratio of the area of the crystallization curve from the initial crystallization temperature to the crystallization temperature $T$ to the area of the whole crystallization peak.

Generally, the relationship between relative crystallinity and crystallization temperature can be expressed as follows:

$$
X_{t}=\frac{\int_{T_{0}}^{T} \frac{\mathrm{d} H_{\mathrm{c}}(T)}{\mathrm{d}(T)}}{\int_{T_{0}}^{T_{\infty}} \frac{\mathrm{d} H_{\mathrm{c}}(T)}{\mathrm{d}(T)}}
$$

where $T_{0}$ and $T_{\infty}$ correspond to the initial and end temperatures of the crystallization curve, respectively. And $T$ represents the crystallization temperature at time $t$. Fig. 5 presents the plots of $X_{t}$ versus $T$ according to eqn (1) for nylon $10 \mathrm{~T} / 66$, nylon $10 \mathrm{~T} / 66 /$ $\mathrm{TiO}_{2}$, nylon $10 \mathrm{~T} / 66 / \mathrm{GF}$ and nylon $10 \mathrm{~T} / 66 / \mathrm{TiO}_{2} / \mathrm{GF}$. It can be clearly seen that all the curves show reverse $\mathrm{S}$ shape, implying that the cooling rate has a retardation effect on the crystallization. In addition, the lower crystallization onset temperature of all samples was obtained along with the increase of cooling rate, which could be attributed to the higher cooling rate causes the molecular chain to have insufficient time to start crystallization at a higher temperature.
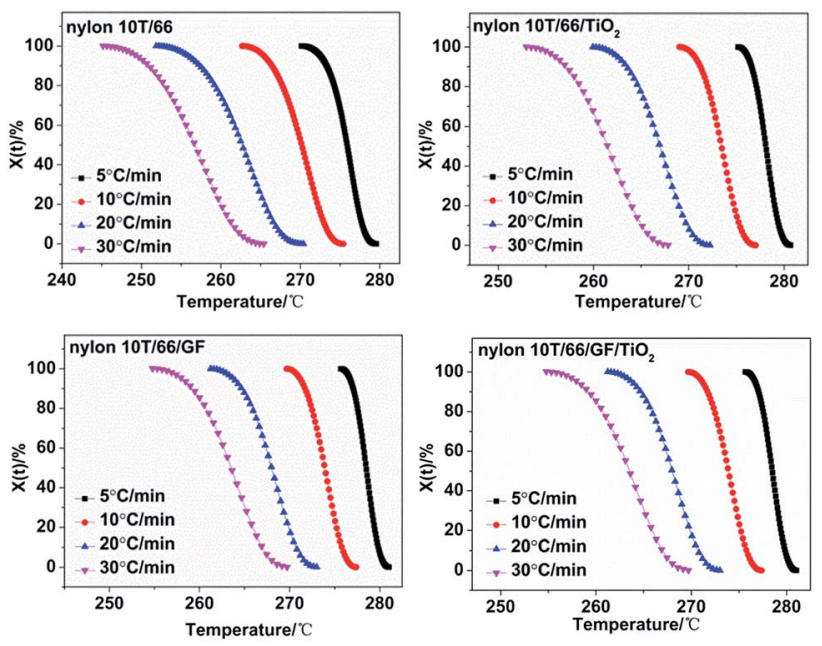

Fig. 5 Plots of $X_{t}$ versus $T$ for nylon $10 \mathrm{~T} / 66$, nylon $10 \mathrm{~T} / 66 / \mathrm{TiO}_{2}$, nylon 10T/66/GF and nylon 10T/66/ $\mathrm{TiO}_{2} / \mathrm{GF}$.

The crystallization time and crystallization temperature can be transformed by the following formula:

$$
t=\frac{T_{0}-T}{\Phi}
$$

where $\Phi$ is the cooling rate. Combining eqn (1) and (2), we got the $X_{t}=f(t)$ curves (Fig. 6). The time corresponding to the $50 \%$ relative crystallinity $\left(t_{1 / 2}\right)$ can be obtained from the Fig. 6 . And the crystallization rate $G=1 / t_{1 / 2}$, which is listed in Table $2 .{ }^{21}$ According to the theory of crystallization kinetics, the bigger value of $G$ means the faster crystallization rate. ${ }^{22}$ As presented in Table 2, for each sample, $t_{1 / 2}$ decreases and $G$ increases gradually as the cooling rate increases, indicating faster crystallization rate at the high cooling rate. Interestingly, at the same cooling rate, with the addition of GF and $\mathrm{TiO}_{2}$, the crystallization rate increases, which further confirmed they play important roles in the hetero-geneous nucleation. Moreover, the
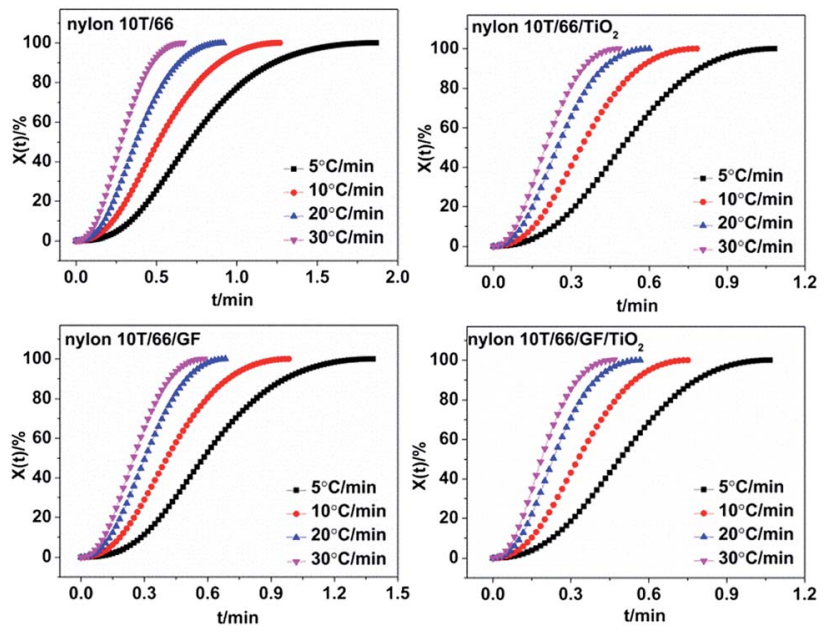

Fig. 6 Plots of $X_{t}$ versus $t$ for nylon $10 \mathrm{~T} / 66$, nylon $10 \mathrm{~T} / 66 / \mathrm{TiO}_{2}$, nylon 10T/66/GF and nylon 10T/66/ $\mathrm{TiO}_{2} / \mathrm{GF}$. 
fastest crystallization rate of nylon $10 \mathrm{~T} / 66 / \mathrm{TiO}_{2} / \mathrm{GF}$ could be ascribed to the synergistic of the $\mathrm{TiO}_{2}$ and GF.

As for the crystallization rate of the nylon $10 \mathrm{~T} / 66 / \mathrm{TiO}_{2}$ is faster than nylon $10 \mathrm{~T} / 66 / \mathrm{GF}$, it is because that the smaller particle size of $\mathrm{TiO}_{2}$ promotes heterogeneous nucleation to a greater extent.

3.4.3 Jeziorny equation. In order to study the crystallization mechanism of the materials, some equations were choosen to analysis the crystallization kinetics. Generally, Avrami equation (eqn (3)) is one of the most common methods for investigating the isothermal crystallization processes. ${ }^{19}$

$$
X_{t}=1-\exp \left(-Z_{t} t^{n}\right)
$$

Taking the logarithms of both sides, we can obtain:

$$
\lg \left[-\ln \left(1-X_{t}\right)\right]=n \lg t+\lg Z_{t}
$$

where $n$ is Avrami index and $Z_{t}$ is the crystallization rate constant. Regrettably, Avrami equation is unsuited for describing non-isothermal crystallization process. ${ }^{23}$ In order to analysis the non-isothermal crystallization process, Jeziorny modified $Z_{t}$ with the cooling rate, and the modified equation is as follow: ${ }^{24}$

$$
\lg Z_{\mathrm{c}}=\frac{\lg Z_{t}}{\Phi}
$$

where $Z_{\mathrm{c}}$ denotes non-isothermal crystallization rate constant. On the basis of eqn (4), the plots of $\lg \left[-\ln \left(1-X_{t}\right)\right]$ against $\lg t$ at different cooling rates are shown in Fig. 7. The $n$ and $Z_{\mathrm{c}}$ can be determined from the slope and intercept, and they are presented in Table 3. As listed in Table 3, the $n$ for nylon 10T/66, nylon $10 \mathrm{~T} / 66 / \mathrm{TiO}_{2}$, nylon $10 \mathrm{~T} / 66 / \mathrm{GF}$ and nylon $10 \mathrm{~T} / 66 / \mathrm{TiO}_{2} /$ GF ranges from 2.17 to $2.44,1.84$ to $2.22,2.09$ to 2.29 and 1.89 to 2.29 , which indicates that the mode of the nucleation and growth for these nylons may be one-dimensional and twodimensional coexistence. As we all know, larger $Z_{\mathrm{c}}$ value corresponds to faster crystallization rate. ${ }^{24} \mathrm{The} Z_{\mathrm{c}}$ increased gradually
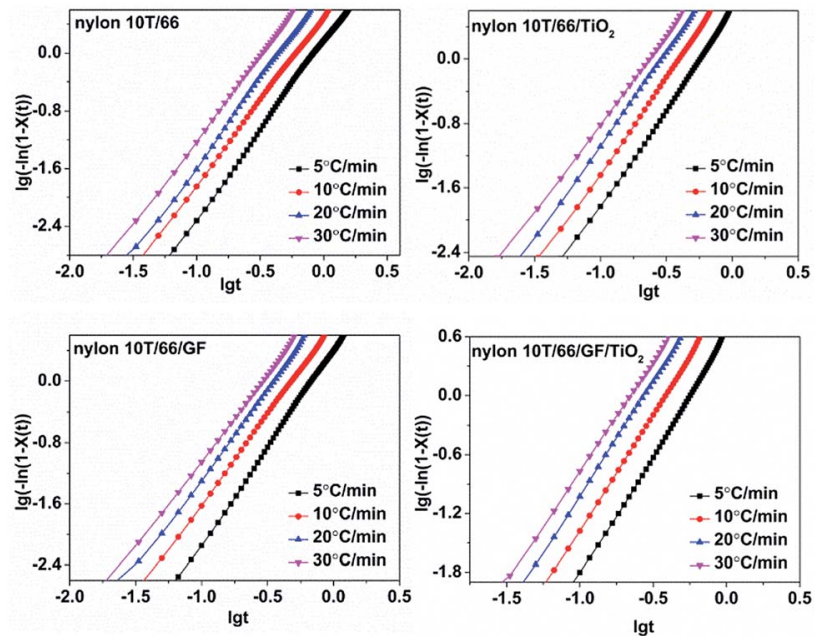

Fig. 7 Plots of $\lg \left[-\ln \left(1-X_{t}\right)\right]$ versus $\lg t$ for nylon 10T/66, nylon 10T/

\begin{tabular}{|c|c|c|c|c|}
\hline Sample & $\Phi /{ }^{\circ} \mathrm{C} \min ^{-1}$ & $n$ & $Z_{t}$ & $Z_{\mathrm{c}}$ \\
\hline \multirow[t]{4}{*}{ Nylon $10 \mathrm{~T} / 66$} & 5 & 2.27 & 0.90 & 0.98 \\
\hline & 10 & 2.17 & 2.03 & 1.07 \\
\hline & 20 & 2.34 & 5.58 & 1.09 \\
\hline & 30 & 2.44 & 16.22 & 1.10 \\
\hline \multirow[t]{4}{*}{ Nylon $10 \mathrm{~T} / \mathrm{TiO}_{2}$} & 5 & 2.02 & 1.45 & 1.08 \\
\hline & 10 & 1.84 & 2.63 & 1.10 \\
\hline & 20 & 2.14 & 8.51 & 1.11 \\
\hline & 30 & 2.22 & 25.70 & 1.11 \\
\hline \multirow[t]{4}{*}{ Nylon $10 \mathrm{~T} / 66 / \mathrm{GF}$} & 5 & 2.29 & 1.42 & 1.07 \\
\hline & 10 & 2.08 & 2.24 & 1.08 \\
\hline & 20 & 2.09 & 6.31 & 1.10 \\
\hline & 30 & 2.27 & 16.60 & 1.10 \\
\hline \multirow{4}{*}{ Nylon $10 \mathrm{~T} / 66 / \mathrm{TiO}_{2} / \mathrm{GF}$} & 5 & 2.03 & 1.51 & 1.09 \\
\hline & 10 & 1.89 & 3.16 & 1.12 \\
\hline & 20 & 2.08 & 11.22 & 1.13 \\
\hline & 30 & 2.29 & 33.88 & 1.13 \\
\hline
\end{tabular}
$66 / \mathrm{TiO}_{2}$, nylon 10T/66/GF and nylon 10T/66/ $/ \mathrm{TiO}_{2} / \mathrm{GF}$.
Table 3 The parameters determined by Jeziorny method

when increasing the cooling rate, meaning the crystallization rate increases. For a given cooling rate, the $Z_{\mathrm{c}}$ values of nylon $10 \mathrm{~T} / 66 / \mathrm{TiO}_{2}$ and nylon $10 \mathrm{~T} / 66 / \mathrm{GF}$ are both higher than nylon 10T/66. This indicates that the $\mathrm{TiO}_{2}$ and GF are efficient in accelerating the crystallization nylon $10 \mathrm{~T} / 66$. In addition, the nylon $10 \mathrm{~T} / 66 / \mathrm{TiO}_{2} / \mathrm{GF}$ has the fastest crystallization rate due to the synergistic of the $\mathrm{TiO}_{2}$ and GF. All these conclusions are consistent with the previous results of $G$.

3.4.4 Mo equation. Ozawa equation, another method to depict crystallization, has been proved by many articles to be unsuitable for describing non-isothermal crystallization of polymers. ${ }^{25,26}$ However, Mo et al. proposed a new method (eqn (6)) combining Avrami and the Ozawa equations, which could describe the non-isothermal crystallization kinetics more accurately. ${ }^{27,28}$

$$
\begin{gathered}
\lg Z_{t}+n \lg t=\lg K(T)-m \lg \Phi \\
\lg \Phi=\lg F(T)-\alpha \lg t
\end{gathered}
$$

where $\alpha=n / m$ ( $n$, Avrami exponent and $m$, Ozawa exponent) and $F(T)$ represents the cooling rate required to reach a relative crystallinity at a unit time. ${ }^{29}$ Many studies have identified that Mo equation could well describe the non-isothermal crystallization behaviors of polymers, such as the poly(vinyl alcohol)/ starch composite, ${ }^{30}$ poly(ethylene terephthalate) composites ${ }^{31}$ and poly(butylene succinate) (PBS). ${ }^{20}$ Fig. 8 shows the curves of $\lg \Phi$ versus $\lg t$ of nylon $10 \mathrm{~T} / 66$, nylon $10 \mathrm{~T} / 66 / \mathrm{TiO}_{2}$, nylon $10 \mathrm{~T} /$ $66 / \mathrm{GF}$ and nylon $10 \mathrm{~T} / 66 / \mathrm{TiO}_{2} / \mathrm{GF}$ with a series of straight lines (the correlation coefficient $R^{2}$ is shown in Table 4, they are all less than 0.99), which indicates the Mo equation is also suitable for analyzing the non-isothermal crystallization behaviors of these nylons. The $\alpha$ and $F(T)$ could be obtained from the slopes and the intercepts, and the values are listed in Table 4 . Usually, the bigger $F(T)$ value means the slower crystallization rate. ${ }^{22}$ It can be clearly seen from Table 4 that the values of $F(T)$ increases with the relative crystallinity, which indicates that if we want to reach a large relative crystallinity within a certain period of time, we must achieve this by increasing the cooling 

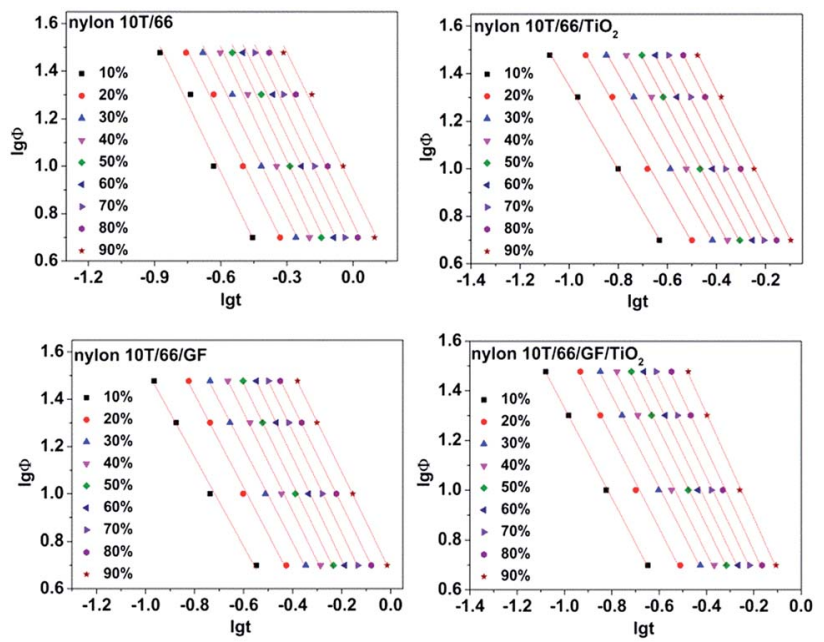

Fig. 8 Plots of $\lg \Phi$ versus $\lg t$ for nylon $10 \mathrm{~T} / 66$, nylon $10 \mathrm{~T} / 66 / \mathrm{TiO}_{2}$, nylon 10T/66/GF and nylon $10 \mathrm{~T} / 66 / \mathrm{TiO}_{2} / \mathrm{GF}$.

Table 4 Parameters of non-isothermal crystallization kinetics by the Mo equation

\begin{tabular}{|c|c|c|c|c|}
\hline Sample & $X(t)(\%)$ & $\alpha$ & $F(t)$ & $R^{2}$ \\
\hline \multirow[t]{9}{*}{ Nylon 10T/66 } & 10 & 1.92 & 0.66 & 0.97 \\
\hline & 20 & 1.87 & 1.21 & 0.99 \\
\hline & 30 & 1.89 & 1.66 & 0.99 \\
\hline & 40 & 1.97 & 2.09 & 0.99 \\
\hline & 50 & 1.97 & 2.70 & 0.98 \\
\hline & 60 & 1.93 & 3.52 & 0.98 \\
\hline & 70 & 1.94 & 4.44 & 0.99 \\
\hline & 80 & 1.96 & 5.75 & 0.99 \\
\hline & 90 & 1.91 & 8.00 & 0.99 \\
\hline \multirow[t]{9}{*}{ Nylon $10 \mathrm{~T} / \mathrm{TiO}_{2}$} & 10 & 1.75 & 0.39 & 1.00 \\
\hline & 20 & 1.82 & 0.60 & 1.00 \\
\hline & 30 & 1.83 & 0.87 & 1.00 \\
\hline & 40 & 1.91 & 1.04 & 1.00 \\
\hline & 50 & 1.95 & 1.25 & 1.00 \\
\hline & 60 & 1.98 & 1.55 & 1.00 \\
\hline & 70 & 2.02 & 1.89 & 1.00 \\
\hline & 80 & 2.05 & 2.41 & 1.00 \\
\hline & 90 & 2.07 & 3.14 & 1.00 \\
\hline \multirow[t]{9}{*}{ Nylon $10 \mathrm{~T} / 66 \mathrm{~F}$} & 10 & 1.88 & 0.45 & 0.99 \\
\hline & 20 & 1.97 & 0.70 & 0.99 \\
\hline & 30 & 2.00 & 0.99 & 1.00 \\
\hline & 40 & 2.09 & 1.23 & 1.00 \\
\hline & 50 & 2.12 & 1.56 & 1.00 \\
\hline & 60 & 2.17 & 1.93 & 1.00 \\
\hline & 70 & 2.14 & 2.55 & 1.00 \\
\hline & 80 & 2.10 & 3.42 & 1.00 \\
\hline & 90 & 2.12 & 4.66 & 1.00 \\
\hline \multirow[t]{9}{*}{ Nylon $10 \mathrm{~T} / 66 / \mathrm{TiO}_{2} / \mathrm{GF}$} & 10 & 1.81 & 0.33 & 1.00 \\
\hline & 20 & 1.85 & 0.55 & 0.99 \\
\hline & 30 & 1.85 & 0.80 & 1.00 \\
\hline & 40 & 1.91 & 0.96 & 1.00 \\
\hline & 50 & 1.93 & 1.21 & 1.00 \\
\hline & 60 & 1.97 & 1.45 & 1.00 \\
\hline & 70 & 1.99 & 1.81 & 1.00 \\
\hline & 80 & 2.04 & 2.23 & 1.00 \\
\hline & 90 & 2.10 & 2.94 & 1.00 \\
\hline
\end{tabular}

rate. For the same relative crystallinity, the $F(T)$ values of nylon $10 \mathrm{~T} / 66 / \mathrm{GF}$ and nylon $10 \mathrm{~T} / 66 / \mathrm{TiO}_{2}$ are both lower than that of nylon $10 \mathrm{~T} / 66$, and the value of nylon $10 \mathrm{~T} / 66 / \mathrm{TiO}_{2} / \mathrm{GF}$ is the lowest. These indicate that nylon $10 \mathrm{~T} / 66 / \mathrm{GF}$ and nylon $10 \mathrm{~T} / 66 /$ $\mathrm{TiO}_{2}$ have faster crystallization rate than nylon $10 \mathrm{~T} / 66$, and nylon $10 \mathrm{~T} / 66 / \mathrm{TiO}_{2} / \mathrm{GF}$ has the fastest crystallization rate, which are in perfect accordance with the results of the Jeziorny analysis.

3.4.5 Crystallization activation energy. Activation energy is an important parameter in the phase transition process, which is related to the energy and barrier of phase transition. ${ }^{32}$ Activation energy could effectively reflect the crystallization ability of polymers. ${ }^{33}$

Kissinger $^{34}$ is the most common method for calculating crystallization activation energy. ${ }^{35}$

$$
\frac{\mathrm{d}\left[\ln \left(\Phi / T_{\mathrm{P}}^{2}\right)\right]}{\mathrm{d}\left(1 / T_{\mathrm{P}}\right)}=-\frac{E}{R}
$$

where $E$ denotes the activation energy. The plots of $\ln \left(\Phi / T_{\mathrm{p}}{ }^{2}\right)$ versus $1 / T_{\mathrm{p}}$ is shown in Fig. 9. The activation energy could be calculated from the slope of the plots (see Table 5). As listed in Table 5 , the $R^{2}$ of these samples are less than 0.97 , which mean that the lines have a good linear relationship. It also can be clearly found that adding $\mathrm{GF}$ and $\mathrm{TiO}_{2}$ reduces the $E$ value and the $E$ value of nylon $10 \mathrm{~T} / 66 / \mathrm{TiO}_{2} / \mathrm{GF}$ is the lowest. In other word, adding GF and $\mathrm{TiO}_{2}$ improves the crystallization rate of nylon 10T/66 and nylon $10 \mathrm{~T} / 66 / \mathrm{TiO}_{2} / \mathrm{GF}$ has the most fast crystallization rate.

\subsection{XRD analysis}

The XRD patterns of different samples are showed in Fig. 10. It can be clearly seen that broad diffraction peaks which belong to

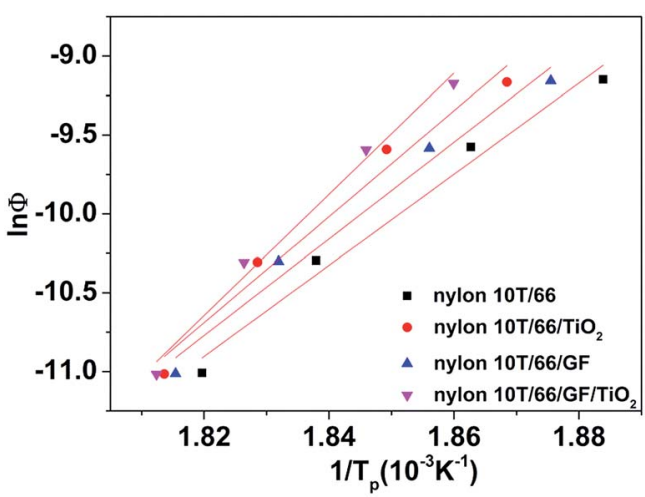

Fig. 9 Plots of $\ln \left(\Phi / T_{\mathrm{p}}^{2}\right)$ versus $1 / T_{\mathrm{p}}$.

Table 5 Activation energy determined by Kissinger

\begin{tabular}{|c|c|c|c|c|}
\hline Sample & $\begin{array}{l}\text { Nylon } \\
10 \mathrm{~T} / 66\end{array}$ & $\begin{array}{l}\text { Nylon } \\
10 \mathrm{~T} / \mathrm{TiO}_{2}\end{array}$ & $\begin{array}{l}\text { Nylon } \\
10 \mathrm{~T} / 66 \text { /GF }\end{array}$ & $\begin{array}{l}\text { Nylon } \\
10 \mathrm{~T} / 66 / \mathrm{TiO}_{2} / \mathrm{GF}\end{array}$ \\
\hline$E /\left(\mathrm{kJ} \mathrm{mol}^{-1}\right)$ & -240.23 & -279.38 & -254.82 & -319.67 \\
\hline$R^{2}$ & 0.97 & 0.97 & 0.97 & 0.98 \\
\hline
\end{tabular}




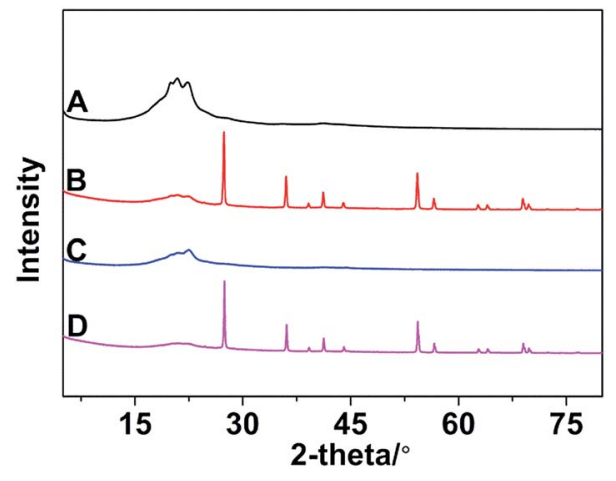

Fig. 10 The XRD patterns of nylon $10 T 66(A)$, nylon $10 \mathrm{~T} / 66 / \mathrm{TiO}_{2}(\mathrm{~B})$, nylon 10T/66/GF (C) and nylon 10T/66/TiO $/$ /GF (D).

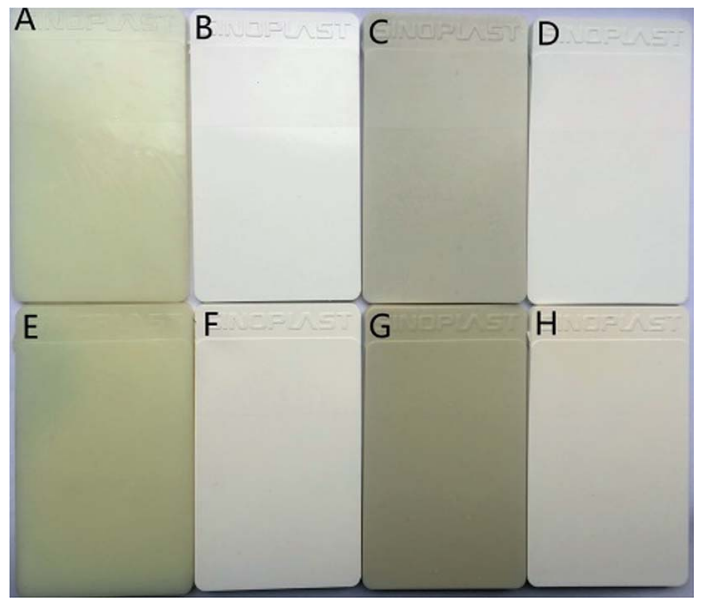

Fig. 11 Plates of nylon 10T/66 (A and E), nylon 10T/66/TiO 2 (B and F), nylon 10T/66/GF ( $\mathrm{C}$ and $\mathrm{G}$ ) and nylon $10 \mathrm{~T} / 66 / \mathrm{TiO}_{2} / \mathrm{GF}(\mathrm{D}$ and $\mathrm{H})(0 \mathrm{~h}$ : $A-D, 2$ h: E-H). crystal of nylon $10 \mathrm{~T} / 66$ appeared at about $20^{\circ}$ in all samples. Other poignant peaks are compounding to the rutile $\mathrm{TiO}_{2}$ existing in nylon $10 \mathrm{~T} / 66 / \mathrm{TiO}_{2}$ and nylon $10 \mathrm{~T} / 66 / \mathrm{TiO}_{2} / \mathrm{GF}$. And there are no diffraction peaks caused by GF both in nylon 10T/66/GF and nylon $10 \mathrm{~T} / 66 / \mathrm{TiO}_{2} / \mathrm{GF}$ owing the cladding of outer substrates.

\subsection{Color comparison and yellowing resistance}

Fig. 11 is the color plates the nylon $10 \mathrm{~T} / 66$, nylon $10 \mathrm{~T} / 66 / \mathrm{TiO}_{2}$, nylon $10 \mathrm{~T} / 66 / \mathrm{GF}$ and nylon $10 \mathrm{~T} / 66 / \mathrm{TiO}_{2} / \mathrm{GF}$ after 0 or 2 hours of thermal oxidation aging at $180{ }^{\circ} \mathrm{C}$. It can be clearly seen from Fig. 11 that the addition of $\mathrm{TiO}_{2}$ can significantly improve the whiteness of nylon $10 \mathrm{~T} / 66$ whether 0 or 2 hours of thermal oxygen aging. Although the whiteness of nylon $10 \mathrm{~T} / 66 / \mathrm{TiO}_{2} / \mathrm{GF}$ has a small decrease compared with nylon $10 \mathrm{~T} / 66 / \mathrm{TiO}_{2}$, it still has a significant improvement over nylon 10T/66.

Table 6 shows the comparison of $L$ and $b$ values for different samples. The larger the $L$ and the $b$ values, the whiter and yellower color of the material, respectively. ${ }^{36,37}$ As shown in Table 6, nylon $10 \mathrm{~T} / 66 / \mathrm{TiO}_{2} / \mathrm{GF}$ has lager $L$ values and smaller $b$ values than nylon 10T/66 whether it is 0 or 2 hours of the hot oxygen aging, which means that the color of the nylon $10 \mathrm{~T} / 66 / \mathrm{TiO}_{2} / \mathrm{GF}$ is whiter. This result is same as the visual observation of Fig. 11.

In addition, the degree of yellowing, an important indicator of the heat-resistant plastics, could be well reflected by the magnitude of the change in $\Delta b$ value, which is equal to $b(2 \mathrm{~h})$ minus $b(0 \mathrm{~h})$. As shown in Table 6, the $\Delta b$ value of nylon $10 \mathrm{~T} / 66 /$ $\mathrm{TiO}_{2} / \mathrm{GF}$ is significantly lower than that of neat nylon $10 \mathrm{~T} / 66$, indicating that nylon $10 \mathrm{~T} / 66 / \mathrm{TiO}_{2} / \mathrm{GF}$ has better yellowing resistance neat nylon 10T/66.

\subsection{Mechanical properties}

The mechanical performance parameters of the nylon 10T/66, nylon $10 \mathrm{~T} / 66 / \mathrm{TiO}_{2}$, nylon $10 \mathrm{~T} / 66 / \mathrm{GF}$ and nylon $10 \mathrm{~T} / 66 / \mathrm{TiO}_{2} /$ GF are summarized in Table 7. It can be observed that the tensile strength, elongation at break and impact strength of

Table 6 The comparison of $L$ and $b$ values for different samples

\begin{tabular}{llcrlr}
\hline Sample & & Nylon $10 \mathrm{~T} / 66$ & Nylon $10 \mathrm{~T} / 66 / \mathrm{TiO}_{2}$ & Nylon $10 \mathrm{~T} / 66 / \mathrm{GF}$ & Nylon $10 \mathrm{~T} / 66 / \mathrm{TiO} / \mathrm{GF}$ \\
\hline \multirow{2}{*}{$L$} & $0 \mathrm{~h}$ & 82.20 & 97.16 & 79.37 & 95.04 \\
& $2 \mathrm{~h}$ & 80.53 & 96.01 & 77.91 & 93.76 \\
$b$ & $0 \mathrm{~h}$ & 10.24 & 2.93 & 9.43 & 2.99 \\
& $2 \mathrm{~h}$ & 13.34 & 5.49 & 13.20 & 5.75 \\
& $\Delta b$ & 3.1 & 2.56 & 3.77 & 2.76
\end{tabular}

Table 7 The mechanical properties of different samples

\begin{tabular}{|c|c|c|c|c|c|}
\hline Samples & Tensile strength $[\mathrm{MPa}]$ & $\begin{array}{l}\text { Breaking elongation } \\
{[\%]}\end{array}$ & Bending strength [MPa] & Bending modulus [MPa] & $\begin{array}{l}\text { Impact strength } \\
{\left[\mathrm{kJ} \mathrm{m}^{2}\right]}\end{array}$ \\
\hline Nylon 10T/66 & $49.56 \pm 3.54$ & $3.66 \pm 0.33$ & $89.79 \pm 2.9$ & $2375 \pm 63.73$ & $5.9 \pm 0.4$ \\
\hline Nylon $10 \mathrm{~T} / 66 / \mathrm{GF}$ & $98.96 \pm 1.73$ & $3.99 \pm 0.1$ & $141.79 \pm 2.12$ & $5845 \pm 0$ & $5.51 \pm 0.35$ \\
\hline Nylon $10 \mathrm{~T} / 66 / \mathrm{TiO}_{2} / \mathrm{GF}$ & $72.59 \pm 5.65$ & $3.19 \pm 0.15$ & $129.29 \pm 1.41$ & $5640 \pm 91.92$ & $4.5 \pm 0.49$ \\
\hline
\end{tabular}


nylon 10T/66 decreased with the addition of $\mathrm{TiO}_{2}$. However, the tensile strength, flexural strength and flexural modulus are obviously improved by introducing GF, while the elongation at break and impact strength are comparable to nylon 10T/66. These phenomena are attributed that the addition of GF promotes the crystallization and increases surface fracture energy of nylon. Also, it is due to the rigidization effect of GF within the nylon and higher modulus of GF as compared with nylon. ${ }^{8,9}$ Clearly, although the mechanical properties of nylon $10 \mathrm{~T} / 66 / \mathrm{TiO}_{2} / \mathrm{GF}$ are lower than those of nylon $10 \mathrm{~T} / 66 / \mathrm{GF}$, there is still a significant increase compared with neat nylon 10T/66.

\section{Conclusions}

In this paper, we prepared nylon $10 \mathrm{~T} / 66 / \mathrm{TiO}_{2} / \mathrm{GF}$ by blending assynthesised nylon 10T/66 with $\mathrm{TiO}_{2}$ and GF. The non-isothermal crystallization behaviors of nylon $10 \mathrm{~T} / 66$, nylon $10 \mathrm{~T} / 66 / \mathrm{TiO}_{2}$, nylon $10 \mathrm{~T} / 66 / \mathrm{GF}$ and nylon $10 \mathrm{~T} / 66 / \mathrm{TiO}_{2} / \mathrm{GF}$ were investigated. The crystallization curves showed that nylon $10 \mathrm{~T} / 66 / \mathrm{TiO}_{2} / \mathrm{GF}$ has a higher crystallization temperature than nylon 10T/66. The crystallization rate $G$, Jeziorny and Mo analysis revealed that nylon $10 \mathrm{~T} / 66 / \mathrm{TiO}_{2} / \mathrm{GF}$ has higher crystallization rate. The Kissinger method was used to calculate the non-isothermal crystallization activation energies, indicating that the $E$ value of nylon $10 \mathrm{~T} / 66 / \mathrm{TiO}_{2} / \mathrm{GF}$ is lower than nylon $10 \mathrm{~T} / 66$. All these results can be attributed to that $\mathrm{GF}$ and $\mathrm{TiO}_{2}$ play strong crucial roles in the heterogeneous nucleation. The color comparison and mechanical properties showed that the yellowing resistance and mechanical properties of nylon $10 \mathrm{~T} / 66 / \mathrm{TiO}_{2} / \mathrm{GF}$ were better than nylon $10 \mathrm{~T} / 66$. The nylon $10 \mathrm{~T} / 66 / \mathrm{TiO}_{2} / \mathrm{GF}$ composites possesses higher crystallization temperature, crystallization rate, whiter color, better yellowing resistance and mechanical properties, and has promising applicability in the field of LED lights.

\section{Conflicts of interest}

There are no conflicts to declare.

\section{Acknowledgements}

Thanks for the NMR testing support of Platform for Science and Technology, Shenzhen Institutes of Advanced Technology, Chinese Academy of Sciences.

\section{Notes and references}

1 Y. J. Kim, K. E. Yohana, H. Lee and J. Kim, Ind. Eng. Chem. Res., 2012, 51, 15801-15810.

2 G. Zhang, G. Yan, T. Yu, J. H. Lu, X. Huang, X. Wang and J. Yang, Ind. Eng. Chem. Res., 2017, 56, 9275-9284.

3 M. Cao, C. Zhang, B. He, M. Huang and S. Jiang, Macromol. Res., 2017, 7, 1-8.

4 W. Feng, P. Wang, G. Zou, Z. Ren and J. Ji, Des. Monomers Polym., 2018, 21, 33-42.

5 S. Yang, P. Fu, M. Liu, Y. Wang and Q. Zhao, J. Appl. Polym. Sci., 2010, 4, 1094-1099.
6 C. L. Zhang, L. Wan, X. P. Gu and L. F. Feng, Macromol. React. Eng., 2015, 9, 512-521.

7 Y. Wang, H. L. Kang, R. Wang, R. G. Liu and X. M. Hao, J. Appl. Polym. Sci., 2018, 135, 46409.

8 C. Li and X. Liu, Mater. Lett., 2007, 61, 2239-2242.

9 W. Chen, M. Pang, M. Xiao, S. Wang, L. Wen and Y. Meng, J. Reinf. Plast. Compos., 2009, 29, 1545-1550.

10 C. Li, X. Liu, N. Gao and X. Liu, Mater. Lett., 2008, 62, 194197.

11 Y. Zhongjiu, Xinxingjianzhu Cailiao, 2008, 3, 1-2.

12 S. Wang and Y. Zhang, Fibers Polym., 2014, 15, 1129-1136.

13 A. Layachi, D. Frihi, H. Satha, R. Seguela and S. Gherib, J. Therm. Anal. Calorim., 2018, 124, 1-11.

14 J. Xing, Z. Xu, F. Ruan and B. Deng, High Perform. Polym., 2018, DOI: $10.1177 / 0954008318764584$.

15 A. Jeziorny, Polymer, 1978, 19, 1142-1144.

16 T. Liu, Z. Mo, S. Wang and H. Zhang, Polym. Eng. Sci., 2010, 37, 568-575.

17 H. E. Kissinger, J. Res. Natl. Bur. Stand., 1956, 57, 217-221.

18 Z. Sun, X. Wang, F. Guo, C. Jiang and Q. Pan, Chin. J. Chem. Eng., 2016, 24, 638-645.

19 B. Wang, H. R. Zhang, C. Huang, L. Xiong, J. Luo and X. Chen, RSC Adv., 2017, 7, 42113-42122.

20 T. Yarici, M. Kodal and G. Ozkoc, Polymer, 2018, 146, 361377.

21 F. Zhang, X. Peng, W. Yan, Z. Peng and Y. Shen, J. Polym. Sci., Part B: Polym. Phys., 2011, 49, 1381-1388.

22 R. Yang, L. Ding, X. Zhang and J. Li, Ind. Eng. Chem. Res., 2018, 57, 4978-4987.

23 J. Jiang, E. Zhuravlev, W. B. Hu, C. Schick and D. S. Zhou, Chin. J. Polym. Sci., 2017, 35, 1009-1019.

24 B. Wang, H. R. Zhang, C. Huang, L. Xiong, J. Luo and X. D. Chen, RSC Adv., 2017, 7, 42113-42122.

25 G. P. Desio and L. Rebenfeld, J. Appl. Polym. Sci., 1992, 45, 2005-2020.

26 Y. A. Eltahir, H. A. M. Saeed, Y. Chen, Y. Xia and Y. Wang, J. Polym. Eng., 2014, 34, 353-358.

27 R. M. R. Wellen and E. L. Canedo, J. Mater. Res., 2016, 31, 729-739.

28 J. Augis and J. Bennett, J. Therm. Anal. Calorim., 1978, 13, 283-292.

29 M. Liu, Q. Zhao, Y. Wang, C. Zhang, Z. Mo and S. Cao, Polymer, 2003, 44, 2537-2545.

30 O. A. Bin-Dahman, F. Shehzad and M. A. Al-Harthi, J. Polym. Res., 2018, 25, 5.

31 G. Lin, D. Li, M. Liu, X. Zhang and Y. Zheng, Polymers, 2018, 10, 594.

32 A. Chafidz, I. Ali, R. Elleithy and S. Al-Zahrani, J. Polym. Res., 2012, 19, 9860.

33 N. Bosq and D. Aht-Ong, Macromol. Res., 2018, 26, 13-21.

34 H. Kissinger, Nature, 1964, 201, 68.

35 X. Cui, S. Qing and D. Yan, Eur. Polym. J., 2005, 41, 30603068.

36 M. D. Fairchild and R. S. Berns, Color Res. Appl., 2010, 18, 178-190.

37 P. Ahmadpoor, A. S. Nateri and V. Motaghitalab, J. Appl. Polym. Sci., 2013, 130, 78-85. 